\title{
Benzotrithiophene-Based Donor-Acceptor Copolymers with Distinct Supramolecular Organizations
}

\begin{tabular}{|r|l|}
\hline Journal: & Journal of the American Chemical Society \\
\hline Manuscript ID: & ja-2012-02957s.R1 \\
\hline Danuscript Type: & Communication \\
\hline Complete List of Authors: & $\begin{array}{l}\text { Guo, Xin; Max-Planck-Institute for Polymer Research, } \\
\text { Puniredd, Sreenivasa; Max-Planck-Institute for Polymer Research, } \\
\text { Baumgarten, Martin; Max-Planck-Institute for Polymer Research, } \\
\text { Pisula, Wojciech; Max-Planck-Institute for Polymer Research, } \\
\text { Mullen, Klaus; Max-Planck-Institute for Polymer Research, }\end{array}$ \\
\hline
\end{tabular}


Donor-acceptor (D-A) copolymers have allowed for an effective strategy for tailoring the properties of conjugated polymers for applications in organic photovoltaics (OPV) and organic field-effect transistors (OFET). ${ }^{1}$ The intra- and intermolecular interactions between donor and acceptor units can lead to selfassembly into ordered structures and strong $\pi$-stacking of polymer chains, which both favor the charge carrier transport. Typical donor units originate from electrondonating compounds such as benzo[1,2- $b: 4,5^{-}$ $b$ ']dithiophene, cyclopenta[2,1-b:3,4-b']dithiophene, dithieo[3,2- $\left.b: 2^{\prime}, 3^{\prime}-d\right]$ silole, and dithieo[3,2- $b: 2^{\prime}, 3^{\prime}-$ $d]$ pyrrole, which have been copolymerized with strong acceptors such as 2,1,3-benzothiadiazole (BTZ) to yield high performance organic semiconductors for organic electronics. ${ }^{2}$ In addition to the application of these existing donors, it remains still a great challenge to explore D-A copolymers with new donor or acceptor structures for further understanding the structureproperty relationship and improving the performance of such polymers.

Benzotrithiophenes (BTT) have emerged as a class of attractive building blocks for the design of various types of organic semiconductor materials in recent years. ${ }^{3}$ Exploiting the electron-rich nature, BTT can be expected as a donor unit for the synthesis of narrow band

Scheme 1. Synthesis of monomer 6 and BTTbased D-A copolymers P1 and P2

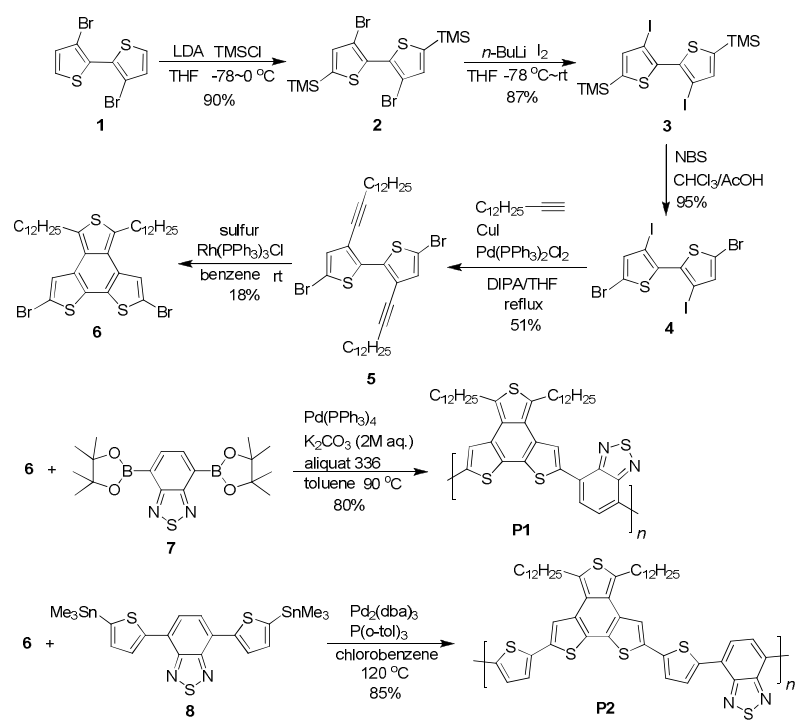

gap D-A copolymers when combined with a suitable acceptor moiety. Furthermore, the coplanarity and extended $\pi$-conjugation of the BTT skeleton should promote intermolecular $\pi$-stacking, which induces strong aggregation and enhanced packing in the solid-state in the BTT-containing polymers. These features are particularly desirable for improving charge carrier transport in OFET devices. Three of seven BTT isomers, namely, benzo[1,2- $b: 3,4-b$ : $: 5,6-$ $\left.b^{\prime \prime}\right]$ trithiophene, ${ }^{3 b-f} \quad$ benzo[1,2-c:3,4-c':5,6$\left.c^{\prime \prime}\right]$ trithiophene, ${ }^{3-i}$ and benzo[2,1-b:-3,4- $b^{\prime}: 5,6-$ $b^{\prime \prime}$ trithiophene, ${ }^{3 j^{-1}}$ have been synthesized and studied intensively (see structures in Figure S1). In particular, McCulloch et al described a benzo[2,1- $b:-3,4-b^{\prime}: 5,6-$ $b^{\prime}$ ']trithiophene-containing D-A copolymer showing potential for application in a bulk heterojunction solar cell. ${ }^{3}$ However, the D-A copolymers containing other BTT isomers have not been synthesized thus far, especially their supramolecular organization and charge carrier transporting property have not been investigated.

Herein, we report the synthesis of two new D-A copolymers, P1 and P2 (Scheme 1) containing the ben- 
zo[2,1-b:3,4-b’:5,6-c']trithiophene as a donor moiety. Table 1. Properties of copolymers P1 and P2

\begin{tabular}{lllll} 
& \multicolumn{3}{c}{$\lambda_{\max }{ }^{\mathrm{abs}}$} \\
\cline { 3 - 5 } polymer & $\mathrm{M}_{\mathrm{n}} / \mathrm{M}_{\mathrm{w}}$ & soln & $\varepsilon$ & film \\
P1 & $(\mathrm{kg} / \mathrm{mol})^{a}$ & $(\mathrm{~nm})^{b}$ & $\left(\mathrm{M}^{-1} \mathrm{~cm}^{-1}\right)^{c}$ & $(\mathrm{~nm})^{d}$ \\
P2 & $19.5 / 38.6$ & 547 & 11400 & 570 \\
& $31.0 / 95.2$ & 645 & 33200 & 645,705
\end{tabular}

\begin{tabular}{lll}
$\mathrm{CV}^{e}$ & & \\
\hline $\mathrm{E}_{\text {HOMо }}$ & $\mathrm{E}_{\mathrm{LUMO}}$ & $\mathrm{E}_{g}{ }^{\mathrm{ec}}$ \\
$(\mathrm{eV})$ & $(\mathrm{eV})$ & $(\mathrm{eV})$ \\
-5.42 & -3.60 & 1.82 \\
-5.36 & -3.45 & 1.91
\end{tabular}

\begin{tabular}{ll} 
OFET & \\
\hline$\mu_{\text {sat, h }}$ & Ion $_{\text {off }}$ \\
$\left(\mathrm{cm}^{2} / \mathrm{V} \mathrm{s}\right)^{f}$ & $(-)^{g}$ \\
n.a. & n.a. \\
0.04 & $\sim 10^{4}$
\end{tabular}

${ }^{a}$ Determined by GPC using polystyrene standard. ${ }^{b}$ Measured in chlorobenzene solutions ( $1 \times 10^{-5} \mathrm{M}$ of repeating unit). ${ }^{c}$ Measured at $\lambda_{\max }{ }^{\text {abs }}$ in solution (per repeating unit). ${ }^{d}$ Drop-cast from chlorobenzene solution (5 mg/mL). ${ }^{e}$ The energy levels and the electrochemical band gaps $\left(\mathrm{E}_{g} \mathrm{ec}\right)$ are determined by cyclic voltammetry measurements (see details in Supporting Information). ${ }^{f}$ Maximum values of hole mobility, after annealing at $200{ }^{\circ} \mathrm{C}$ for $1 \mathrm{hr} .{ }^{g}$ Current on/off ratios.

than all other BTT isomers being a potential donor component for D-A copolymers as described in our recent work. 4 It is worth noting that the dodecyl chains introduced at the 4,6-positions of this BTT donor for solubility almost lie in the same plane with the conjugated core and stretch out along an angle of $c a .55^{\circ}$ with respect to the $C 2$ symmetry axis, as shown in the single crystal of the alkyls-substituted BTT. 4 This nature of our BTT donor is believed to make the alkyl chains of the corresponding polymers locate in the same plane with the polymer backbone and therefore facilitate the $\pi-\pi$ interactions between the polymer chains much more than other polymers with alkyl chains out of the main chains. As we have found, both copolymers show small $\pi$-stacking distances with 0.35 $\mathrm{nm}$ for P1 and 0.37 $\mathrm{nm}$ for P2. On the other hand, proceeding from $\mathbf{P 1}$ to $\mathbf{P 2}$ by insertion of two thiophene units into the polymer backbone of P2 influences significantly the chain conformation, the supermolecular organization, the film microstructure and thus the charge carrier transport. This provides a deeper understanding of the structure-property relationships of BTT-based D-A copolymers.

The synthesis of the dibrominated BTT monomer 6 with two dodecyl side chains is depicted in Scheme 1. Starting from 3,3'-dibromo-2,2'-bithiophene (1),5 an important intermediate 5,5'-dibromo-3,3'-diiodo-2,2'bithiophene (4) was prepared in an overall yield of $74 \%$ by protecting first the $\alpha$-positions of $\mathbf{1}$ with trimethylsilyl (2), then changing the 3,3'-dibromine to 3,3'diiodine (3) and finally performing the dibromination at the $\alpha$-positions. Compound 4 can be coupled with 1tetradecyne by selective Sonogashira reaction to introduce the solubilizing alkyl chains in a yield of $51 \%$. This precursor 5 was then treated with tris(triphenylphosphine) rhodium(I) chloride to produce the rhodium complex as intermediate. The latter was converted into the monomer $\mathbf{6}$ by adding sulfur powder to form the third thiophene ring. The monomer 6 was carefully purified by column chromatography and recrystallization to ensure sufficient purity for polymerization. It is noteworthy that in this route the dibromination has been executed before the formation of the third thiophene ring. This can avoid the direct dibromination to the alkyl-substituted BTT (an extremely electron-rich system) under harsh conditions as well as the complex purification process to remove mono-bromination impurities.
The polymer P1 was synthesized by Suzuki coupling between monomer 6 and 4,7-bis(boronic acid pinacol ester)-2,1,3-benzothiadiazole (7), ${ }^{2 b}$ whereas the polymer P2 was synthesized by Stille coupling between monomer 6 and 4,7-bis(2-trimethylstannylthien-5-yl)2,1,3-benzothiadiazole (8). ${ }^{6} \mathbf{P 1}$ was obtained as a deep purple solid with good solubility in common organic solvents such as THF, chloroform and chlorobenzene. A number-average molecular weight $\left(M_{\mathrm{n}}\right)$ of $19.5 \mathrm{~kg} / \mathrm{mol}$ with a polydispersity index (PDI) of 1.98 was measured by gel permeation chromatography (GPC) in THF. In contrast, P2 was a deep blue solid and less soluble, which becomes soluble only in chlorinated solvents such as chlorobenzene and $o$-dichlorobenzene after heating above $100{ }^{\circ} \mathrm{C}$. A $M_{\mathrm{n}}$ of $31.0 \mathrm{~kg} / \mathrm{mol}$ with a PDI of 3.07 was measured by GPC in trichlorobenzene (TCB) at $135{ }^{\circ} \mathrm{C}$. The higher molecular weight of $\mathbf{P 2}$ than $\mathbf{P 1}$ is a main reason for poorer solubility of $\mathbf{P 2}$.
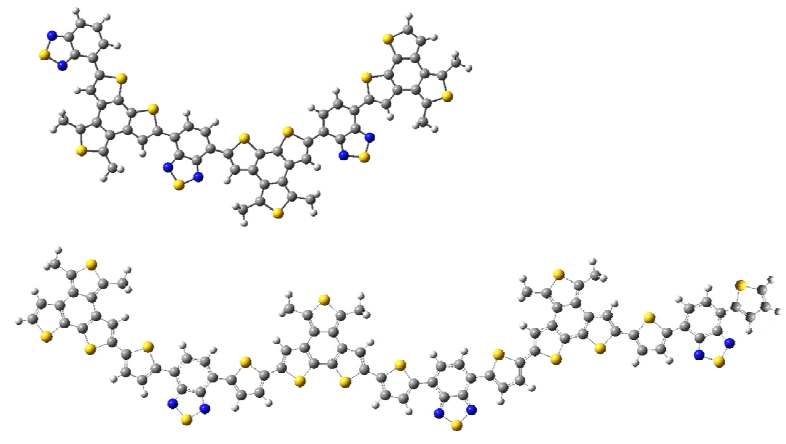

Figure 1. Minimum-energy conformations of methylsubstituted trimers of P1 (top) and P2 (bottom) optimized with Gaussian at the B3LYP/6-31G* level.

Quantum-chemical calculations (B3LYP/6-31G*) were performed to predict the minimum-energy conformations of the trimers of P1 and P2. As illustrated in Figure 1, the alkyl chains of both polymers turn towards the same side of the backbone, however the backbone of $\mathbf{P 1}$ is more curved than P2, which should also somewhat contribute to better solubility of the former. More importantly, the different degree of curvature in the polymer backbone will also influence the supermolecular organization, the film microstructure and the charge carrier mobility of the two polymers.

Both polymers display broad absorption bands with maxima in solution at $547 \mathrm{~nm}$ and $645 \mathrm{~nm}$ for P1 and P2, respectively (Figure $\mathrm{S} 3$ and Table 1). This can be attributed to the strong D-A interaction, indicative of 
BTT a strong donor unit. The red shift of almost 100 $\mathrm{nm}$ upon going from P1 to $\mathbf{P 2}$ is believed to originate from the two inserted thiophene units which provide the extended conjugation and weak electron-donating nature. In the solid state, $\mathbf{P 1}$ shows a red-shifted and broader absorption maximum, which feature can be ascribed to solid-state packing effects, whereas for P2, a strong shoulder at $705 \mathrm{~nm}$ appears, clearly suggesting the formation of a more aggregated conformation in thin film. The optical bandgaps estimated from the onset of the thin-film absorptions are $1.35 \mathrm{eV}$ for $\mathbf{P 1}$ and $1.53 \mathrm{eV}$ for P2, respectively. Compared to the optical bandgap $(1.75 \mathrm{eV})^{31}$ of the D-A copolymer derived from another BTT isomer benzo[2,1- $b:-3,4-b^{\prime}: 5,6-$ $b^{\prime \prime}$ trithiophene and BTZ, P1 shows a narrower optical bandgap, indicating again the stronger electrondonating nature of our BTT donor unit.

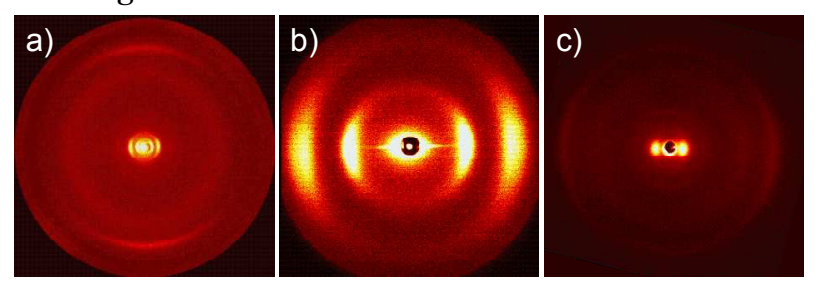

d)

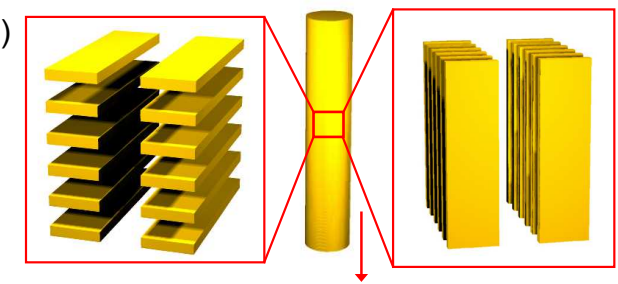

Figure 2. a) WAXS and b) SAXS for P1, c) WAXS for P2, and d) schematic illustration for the polymer arrangement in the extruded fiber for P1 (left) and P2 (right) (red arrow indicates the extrusion/orientation direction).

The supramolecular organization of both polymers, $\mathbf{P 1}$ and P2, in the bulk was investigated by twodimensional wide-angle X-ray scattering (2DWAXS). For this study both polymers were extruded into macroscopically aligned fibers which were mounted vertically towards the $2 \mathrm{D}$ detector. Polymer P2 shows a characteristic 2D pattern for a conjugated polymer (Figure 2c). ${ }^{3 \mathrm{~d}}$ Small-angle reflections in the equatorial plane of the pattern are attributed to a chain-to-chain distance of $2.7 \mathrm{~nm}$ between the lamellar structures, which are aligned along the extrusion direction of the fiber (Figure 2d). The weak equatorial wide-angle scattering intensities are assigned to the $\pi$-stacking of 0.37 $\mathrm{nm}$ of the backbones within the lamellar stacks. Interestingly, the organization of $\mathbf{P 1}$ in the fiber sample differs significantly. Firstly, the chain-to-chain distance of $4.36 \mathrm{~nm}$ is considerably larger in comparison to P2 as derived from the small-angle pattern (Figure 2b) and is attributed to the more pronounced degree of curvature in the backbone of P1, as shown in Figure 1. The corresponding reflections are located on the equatorial plane, while surprisingly, the scattering intensities related to the $\pi$-stacking of $0.35 \mathrm{~nm}$ appear in the wideangle meridional (Figure 2a). Therefore, the polymer chains are arranged perpendicular to the alignment direction of the sample (Figure 2d). This is very untypi- cal for conjugated polymers with a high molecular aspect ratio which is usually the driving force for an alignment of the polymer backbone along the extrusion direction of the sample. Polymer P1 shows an organization identical to discotic columnar systems in which the $\pi$-stacking direction as well as the stacks characteristically orient along the alignment direction. 7 Therefore, the behavior of $\mathbf{P 1}$ can be explained with the disc-like shape of the BTT unit which pack on top of each other thus forming a columnar stack. However, in such a packing motif, the subunits of the same electron affinity have to pack on top of each other and no donoracceptor interactions between the conjugated backbones occur. Recently, we have found such a donordonor/acceptor-acceptor packing for a benzothiadiazole-cyclopentadithiophene polymer..$^{f}$ In the case of P2, the molecular aspect ratio of the repeating unit is increased by extending the length by the two additional thiophene units within the backbone. This leads to the more parallel orientation of the polymer chains to the fiber axis.
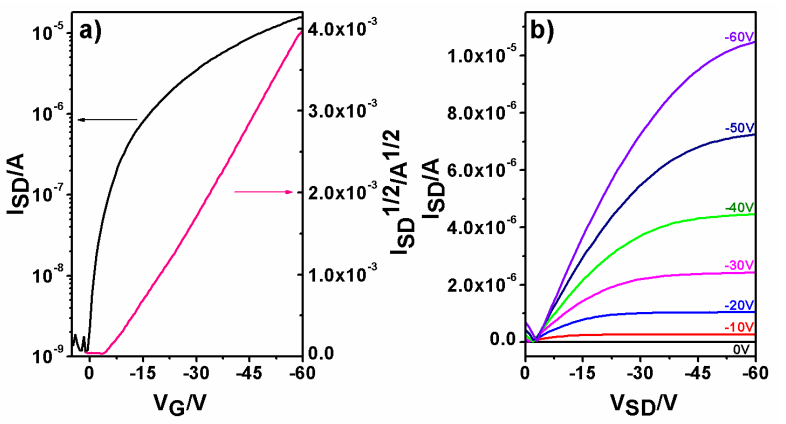

Figure 3. Characteristics for a field-effect transistor of P2: a) transfer curves at a source drain bias of $\mathrm{V}_{\mathrm{SD}}=-60 \mathrm{~V}$ and b) output characteristics at various gate biases $\mathrm{V}_{\mathrm{G}}$.

Bottom-contact, bottom-gate FETs based on the polymers were prepared by drop-casting a dichlorobenzene solution of a concentration of $1 \mathrm{mg} / \mathrm{ml}$ on an HMDS modified, $100{ }^{\circ} \mathrm{C}$ hot $\mathrm{SiO}_{2}$ wafer. After solvent evaporation the films were additionally annealed at $200{ }^{\circ} \mathrm{C}$ for $1 \mathrm{hr}$. Surprisingly, P1 did not show any device performance although good packing was found for the polymer in the bulk with a $\pi$-stacking distance of only 0.35 nm. On the other hand, P2 exhibits typical ptype transistor behavior with hole mobilities up to 0.04 $\mathrm{cm}^{2} / \mathrm{Vs}$ and an average value of $0.01 \mathrm{~cm}^{2} / \mathrm{Vs}$ (Figure 3). The device performance is slightly improved by the modification of the source/drain electrodes with benzenethiol leading to average mobilities of $0.025 \mathrm{~cm}^{2} / \mathrm{Vs}$ for P2 (Figure S6). In contrast to this, under these device conditions polymer P1 still lacks of any field-effect response. To understand the difference in performance of the polymers, grazing incidence wide-angle X-ray (GIWAXS) of the films was performed (Figure 4). Interestingly, the thin layer of $\mathbf{P 1}$ is highly disordered (even amorphous) as indicated by the lack of reflections (Figure $4 \mathrm{a}$ and $4 \mathrm{c}$ ). It seems that solution casting of $\mathbf{P 1}$ on a surface leads to high disorder and therefore inhibits charge carrier transport in the transistor. This is in agreement with our previous findings which suggested that polymers with a high degree of backbone curvature perform poorly in a FET device. ${ }^{8}$ In contrast to this, P2 
is well ordered in the film and edge-on arranged towards the surface as assigned from the out-of-plane reflections for the chain-to-chain distance and the inplane ones for the $\pi$-stacking correlation (Figure $4 \mathrm{~b}$ and $4 \mathrm{~d}$ ). From the equatorial integration along $\mathrm{q}_{\mathrm{z}}=\mathrm{o}$, $\mathrm{a}$ $\pi$-stacking distance of $0.36 \mathrm{~nm}$ for P2 in thin film is derived which is slightly smaller in comparison to that in the bulk (Figure S7). The integration plot for P1 exhibits apart from the pronounced amorphous halo at $1.47 \AA$ Á (Figure S7), which is related to disordered alkyl side chains, also a weak shoulder at $1.72 \AA$. This peak is an indication for some $\pi$-stacking correlations between backbones and thus minor ordering of P1.
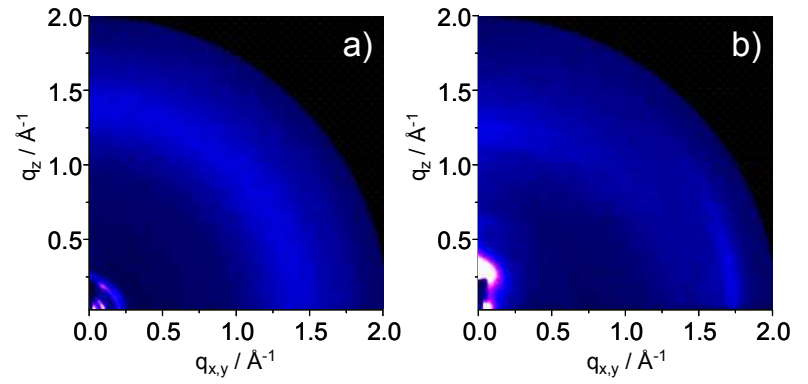

c)

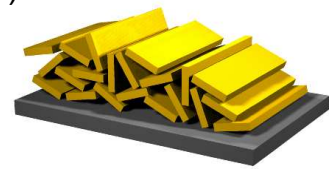

d)

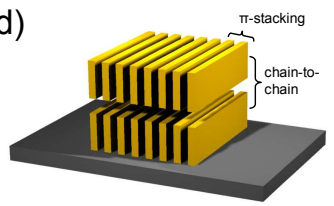

Figure 4. GIWAXS of a) P1 and b) P2 thin films, schematic illustration of the polymer organization on the surface for c) P1 and d) P2 within one single domain.

In conclusion, we have presented two novel benzo[2,1-b:3,4-b':5,6-c']trithiophene-based D-A copolymers, P1 and P2 which exhibit interesting supermolecular organization and promising OFET performance. The structural modification by insertion of two thiophene units into the polymer backbone plays an important role in determining the chain conformation, the supermolecular organization, the film microstructure and thus the charge carrier transport. Polymer P1 does not show any field-effect due to pronounced disorder in the thin film although a distinctive supermolecular structure is observed with a good $\pi$-stacking distance of only $0.35 \mathrm{~nm}$ in the bulk. In stark contrast, polymer $\mathbf{P 2}$ gives a hole mobility of $0.04 \mathrm{~cm}^{2} / \mathrm{Vs}$ which is in agreement with the well-ordered film and the organization into lamellar structures with the $\pi$-stacking distance of $0.37 \mathrm{~nm}$. It is expected that the charge carrier mobility can be further improved by increasing the molecular weight of the polymers or further optimization of the deposition techniques. 9 To the best of our knowledge, this is the first report on BTT-based D-A copolymers which exhibits distinctive supramolecular organization and reasonable field-effect behavior.

\section{ASSOCIATED CONTENT}

Supporting Information. Synthetic details and characterization data. This material is available free of charge via the Internet at http://pubs.acs.org

\section{AUTHOR INFORMATION}

\section{Corresponding Author}

muellen@mpip-mainz.mpg.de

\section{ACKNOWLEDGMENT}

The authors thank Dr. Jie Shu for the measurement of the solid-state $13 \mathrm{C}\{1 \mathrm{H}\}$ CP MAS spectra and for the helpful discussions. X. Guo gratefully acknowledges the Alexander von Humboldt Stiftung for granting a research fellowship. This work was financially supported by the European Community EC-ITN-SUPERIOR (GA-2009-238177) and the ERC Advanced Grant NANOGRAPH (Project Reference No.267160).

\section{REFERENCES}

(1) (a) Günes, S.; Neugebauer, H.; Sariciftci, N. S. Chem. Rev. 2007, 107, 1324. (b) Zhang, L.; Di, C.-a.; Yu, G.; Liu, Y. J. Mater. Chem. 2010, 20, 7059.

(2) (a) Hou, J.; Park, M.-H.; Zhang, S.; Yao, Y.; Chen, L.M.; Li, J.-H.; Yang, Y. Macromolecules 20o8, 41, 6012. (b) Zhang, M.; Tsao, H. N.; Pisula, W.; Yang, C.; Mishra, A. K.; Müllen, K. J. Am. Chem. Soc. 2oo7, 129, 3472. (c) Tsao, H. N.; Cho, D. M.; Park, I.; Hansen, M. R.; Mavrinskiy, A.; Yoon, D. Y.; Graf, R.; Pisula, W.; Spiess, H. W.; Müllen, K. J. Am. Chem. Soc. 2o11, 133, 2605. (d) Beaujuge, P. M.; Pisula, W.; Tsao, H. N.; Ellinger, S.; Müllen, K.; Reynolds, J. R. J. Am. Chem. Soc. 2009, 131, 7514. (e) Hou, J.; Chen, H.-Y.; Zhang, S.; Li, G.; Yang, Y. J. Am. Chem. Soc. 2oo8, 130, 16144. (f) Zhou, E.; Nakamura, M.; Nishizawa, T.; Zhang, Y.; Wei, Q.; Tajima, K.; Yang, C.; Hashimoto, K. Macromolecules 2oo8, $41,8302$.

(3) (a) Jayasuriya, N.; Kagan, J. J. Org. Chem. 1989, 54, 4203. (b) Taerum, T.; Lukoyanova, O.; Wylie, R. G.; Perepichka, D. F. Org. Lett. 2oo9, 11, 3230. (c) Nicolas, Y.; Blanchard, P.; Levillain, E.; Allain, M.; Mercier, N.; Roncali, J. Org. Lett. 2oo4, 6, 273. (d) Proetzsch, R.; Bieniek, D.; Korte, F. Tetrahedron Letters 1972, 543. (e) Kashiki, T.; Kohara, M.; Osaka, I.; Miyazaki, E.; Takimiya, K. J. Org. Chem. 2o11, 76, 4061. (f) Kashiki, T.; Shinamura, S.; Kohara, M.; Miyazaki, E.; Takimiya, K.; Ikeda, M.; Kuwabara, H. Org. Lett. 2009, 11 2473. (g) Imamura, K.; Takimiya, K.; Aso, Y.; Otsubo, T. Chem. Commun. 1999, 1859. (h) Patra, A.; Wijsboom, Y. H.; Shimon, L. J. W.; Bendikov, M. Angew. Chem., Int. Ed. 2oo7, 46, 8814. (i) Hart, H.; Sasaoka, M. J. Am. Chem. Soc. 1978, 10o, 4326. (j) Nielsen, C. B.; Fraser, J. M.; Schroeder, B. C.; Du, J.; White, A. J. P.; Zhang, W.; McCulloch, I. Org. Lett. 2011, 13, 2414. (k) Schroeder, B. C.; Nielsen, C. B.; Kim, Y. J.; Smith, J; Huang, Z.; Durrant, J.; Watkins, S. E.; Song, K.; Anthopoulos, T. D.; McCulloch, I. Chem. Mater. 2011, 23, 4025. (l) Nielsen, C. B.; Schroeder, B. C.; Hadipour, A.; Rand, B. P.; Watkins, S. E.; McCullocha, I. J. Mater. Chem. 2011, 21, 17642.

(4) Guo, X.; Wang, S.; Enkelmann, V.; Baumgarten, M.; Müllen, K. Org. Lett. 2011, 13, 6062.

(5) Lu, G.; Usta, H.; Risko, C.; Wang, L.; Facchetti, A.; Ratner, M. A.; Marks, T. J. J. Am. Chem. Soc. 2008, 13O, 7670 .

(6) Ong, K.-H.; Lim, S.-L.; Tan, H.-S.; Wong, H.-K.; Li, J.; Ma, Z; Moh, L. C. H.; Lim, S.-H.; de Mello, J. C.; Chen, Z.-K. Adv. Mater. 2011, 23, 1409.

(7) (a) Pisula, W.; Feng, X.; Müllen, K. Adv. Mater. 2010, 22, 3634. (b) Laschat, S.; Baro, A.; Steinke, N.; Giesselmann, F.; Hägele, C.; Scalia, G.; Judele, R.; Kapatsina, E.; Sauer, S.; Schreivogel, A.; Tosoni, M. Angew. Chem. Int. Ed. 2007, 46, 4832.

(8) Rieger, R.; Beckmann, D.; Pisula, W.; Steffen, W.; Kastler, M.; Müllen, K. Adv. Mater. 2010, 22, 83.

(9) Tsao, H. N.; Müllen, K. Chem. Soc. Rev. 2o10, 39, 2372. 
(For Table of Contents Use Only)

\section{Benzotrithiophene-Based Donor-Acceptor Copolymers with Distinct Su- pramolecular Organizations}

Xin Guo, Sreenivasa Reddy Puniredd, Martin Baumgarten, Wojciech Pisula, and Klaus Müllen*

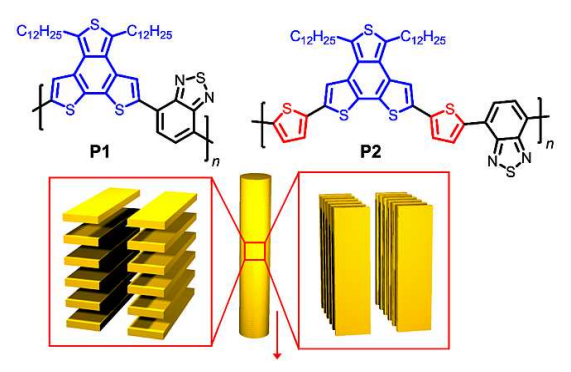

